\title{
Teaching and Learning Writing through Providing Teacher's Feedback
}

\author{
Sihem Boubekeur \\ Djilali Liabes University, Sidi Bel Abbes, Algeria \\ E-mail: mehis_sweety@hotmail.com
}

Received: 05-03- 2015

Published: 01-11- 2015
Accepted: 11-06- 2015

doi:10.7575/aiac.ijalel.v.4n.6p.16
Advance Access Published: August 2015

URL: http://dx.doi.org/10.7575/aiac.ijalel.v.4n.6p.16

\begin{abstract}
Teaching English as a foreign language refers to instructing English to learners who are non native speakers. Mastering the language very well does not mean neither that the teacher can instruct writing in a good way; nor the student can compose coherently. Writing is a fundamental skill in both learning and teaching processes; in which EFL students need to master. Yet; the latter is considered as a complex and difficult task in that learners have to explore their thoughts and ideas via communicating on a paper; but clearly. Thus; since learners are required to write extended essays appropriately; they need to be aware of their mistakes via receiving teachers' feedback which could be an effective strategy that enhances the students' writing capacities.
\end{abstract}

Keywords: EFL, writing, LMD students, strategies, feedback

\section{Introduction}

EFL students' drafting in the classroom is very poor; mainly the case of second year; students of English in Sidi Bel Abbes; Algeria. They regard writing as a complex skill and are unable to master all aspects of writing; and thus; they do not produce acceptable essays. Although learners have dealt with the writing skill for about four semesters; studying three hours per a week and tackling different activities; they are still unable to perform correctly; i.e. they do not use the language appropriately. The hindrances are due to a multitude of factors that hamper the students' performance. In fact; teacher's feedback could be an effective strategy that enhances the learners' written production and makes the students aware of their mistakes.

\subsection{Statement of the Problem}

The problem is mainly related to the fact that the students lack the effective strategies that enable them compose different writing tasks easily and without any obstacle; and consequently produce correct essays. Therefore; they need to be provided with more efficient writing strategies to overcome the hindrances they encounter while writing. Since learning to write coherently is something which many people never know or manage in first and foreign language; it is believed that the mastery of writing requires an understanding of how the writing process works. Through emphasizing not only the product; but also the different stages; the learner goes through. So; teachers are required to help students to have a wholly idea about the successful strategies for writing in English.

Teachers need to take into account students' abilities to produce a piece of writing; starting up from questions such as what shall I write? To whom? For what purpose? Why? Where and how? (Flower and Hayes, 1981: 377). The students' control of writing and the language system can be achieved thanks to the efforts of the teacher to diagnose the real problems; by providing feedback as a strategy with its different types because it is considered as one of the fundamental aspects in the writing process. Writing can be sometimes difficult and frustrating and students need positive feedback and enough success to maintain a willingness to work; Grabe and Kaplan (1996).

Starting from what is mentioned above, the present work addresses the following questions:

1- What lies behind the complexity of the writing skill?

2- Is the focus on feedback a good strategy that helps learners overcome their weaknesses and consequently improve their writing skills?

Thus; the research also addresses the following hypotheses:

1-Writing is a difficult; challenging and troublesome skill.

2- Feedback might be essential in improving and fostering the students' writing.

\subsection{Aims of the study}

The current study shows how second year EFL students write and the problems that they face while drafting. The work focuses primarily on the second year; for the students are required to study for three years in order to get their License Degree, and still encountering hindrances while writing. The most important factor for this selection was that because; it 
is left just one year for the learners to have their degrees. Yet; the writing is flaw. So, written expression is exceedingly crucial for the learners to have it as a module. Despite they have it twice per a week; they still do not know how to write adequate and accurate compositions.

Most of the students and particularly the second year learners are reluctant towards writing and find it a complex skill. In fact; some are good speakers; but drafting in the foreign language is frustrating for them; because of the spelling; grammatical mistakes and the lack of vocabulary. The most important goal of the present work is to show the importance of providing teachers' feedback on the students' compositions. In fact; commenting on the learners' production may enhance their writing skills. Indeed; teachers need to be aware of the impact of their positive response to the students' written production; as well as making the learners appreciate these comments.

\subsection{Data Collection}

The research tries to examine the effectiveness of providing feedback in English as a Foreign Language classroom. A sample of 100 copies have been handed out and only 80 who gave back the questionnaire; they were given to second year; LMD students enrolled in the Department of Languages of the Faculty of Languages and Arts; Section of English in Djilali Liabes University Sidi Bel Abbes; Algeria. The present work is based on two instruments: teachers and students questionnaires. For the use of the structured questionnaire as a technique of research; it is believed that it is the appropriate means for accumulating data about the students' writing practices; attitudes; judgements and a method to find out the answers and findings of a large sample of data collection.

\subsection{Participants}

The learners are second year LMD students who have been enrolled to study English as a foreign language. This instrument has been handed out to three different groups who have totally different level as far as English language is concerned and also their background; i.e. good; average and weak level; and they come from different parts in Algeria; even other countries like Mali. In other words; they have completely various backgrounds and knowledge. The ones who responded are eighty (80) students and give different opinions and attitudes about the writing skill in general and "Written Expression" in particular.

For the teachers; they are also from the same department that is mentioned above. They are eight (08) teachers (males and females) aging between 26 and 55 years old, instructing "Written Expression" module for the second year; they are teaching ten groups; approximately 380 students (males and females, aging between 19 and 40 years old). Each group contains around 35 learners. These teachers are full time instructors who hold the Magister Degree and are also doctorate students; and just one who is a part time teacher and is second year Magister student and she is a novice teacher. The last instructor is a doctor and has a great experience as far as teaching English in general is concerned with

\section{Review of Literature}

\subsection{Definition of writing}

Until the 1960's writing has attracted attention and has been considered as a basic aspect of communication. According to Harmer (1998: 255) the writing skill is recognized as a fundamental skill for language learning; and he stresses mainly on the importance of the writing skill; i.e. he considered the causes for instructing composition to students of English as a foreign language include reinforcement; language development; learning style; and most importantly; writing as a skill. In fact; writing is a complex process; which EFL learners do not acquire naturally; i.e. it is learnt. Written production has been seen as a difficult activity; because it requires the control of the period. He argued that writing ability is a "mental" process; for it is an operation that happens in one's mind. Studies show what our mind can do while composing in order "to create a sort of composition portrait of all the possibilities of mental life when we learn all of the many kinds of knowledge and skill we need in order to compose” (Smit, 2004: 42). Tyner (2008) describes writing as a process of discovery and creation where one word or a sentence may provoke a new idea. It has been identified "as one of the essential skills in a world that is more than ever driven by text and numerical data" (Hyland, 2003). Fulwiler (2002) writing is a way of exploring the world inside and out by the thinker. It is crucial to regard composing not solely as a product of a writer; but as a social and a cultural activity (Weigle, 2002).

\subsection{Definition of feedback}

Feedback is the input from whether a reader/ teacher to a writer through providing the latter with information for revision; in other words, it is the comments; questions and suggestions that the reader gives to the writer. It is via feedback that students appreciate the different aspects of the process of writing, (Flower, 1994). The primary purpose for providing feedback on students' written production is to help them improve the quality of their writing. Indeed, traditional approaches to the teaching of writing assumed that via correcting the students' errors on final drafts, learners would enhance their writing (MacArthur, Graham. \&, Fitzgerld, 2006: 222). In fact, feedback aims at helping students develop their knowledge and strategies for self-correction. Indeed, learners at intermediate and advanced levels appreciate such written responses and ask for it. The most efficient way for providing such feedback is through giving signals or symbols which indicate errors and mistakes. The learners then, have to correct their own mistakes and show the correction to the instructor, (I.S.P. Nation, 2009)

\subsection{The importance of providing feedback}

Teachers' comments help the learners become readers and that latter can make them evaluate their own compositions. According to Sommers (1982: 148) teachers provide feedback on students' written productions in order to motivate the learners to revise. When the teacher identifies the students' errors in usage; diction and style in a first draft and asks the 
students to correct these errors within revision. Such feedback shows the learner the importance of these errors and how they need to regard these errors in this process.

In relation to instructing and learning writing; responding to students' writing is considered as an essential issue; in the sense that writing is recognized as an instrument for ameliorating ideas; constructing thoughts; as well as discovering experiences. Hence; when penning; learners are expected to state their ideas and thoughts adequately and accurately (Aridah, 2003: 6). Accuracy and fluency might be well enhanced when corrective feedback is given. Furthermore; it makes learners be aware of the mistakes that they committed; and eventually; it leads them to fix these mistakes.

\section{Data Analysis and Results}

Question 1: is writing a complex skill to master?

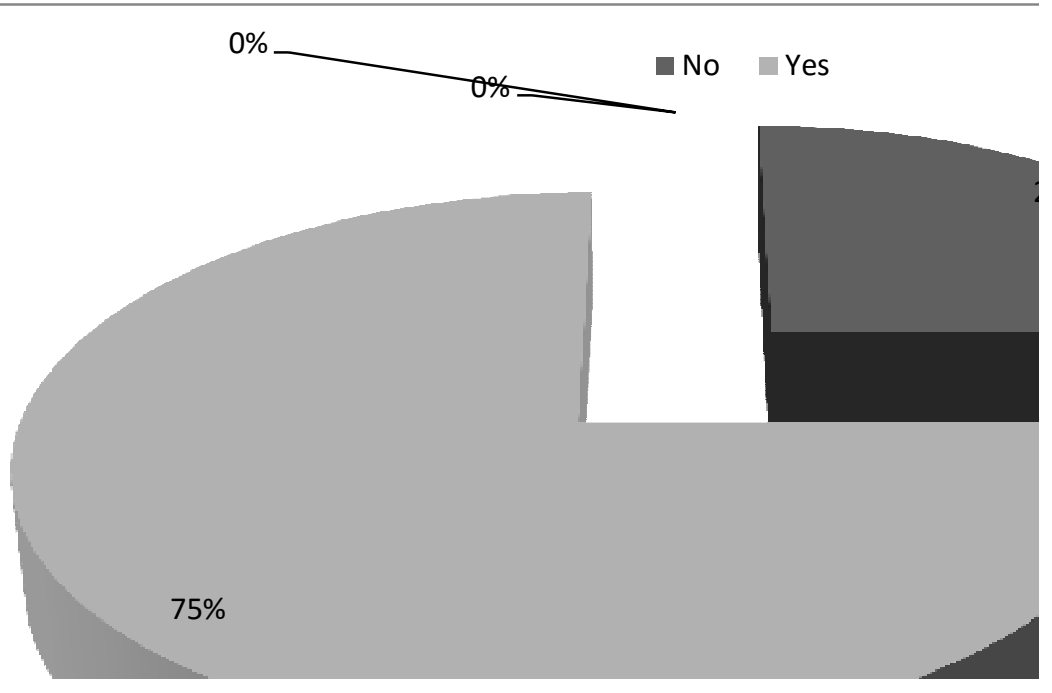

Figure 1. Writing Complexity

The results reveal that $75 \%$ of teachers agreed that writing is difficult and impossible to learn it in a timely period; but it needs more practice. Moreover; it needs a lot of reading in order to be developed. One teacher stated that: "Writing is a skill that needs more practice and enough reading to be mastered". Some questioned teachers explained that writing is a skill that consumes time and teaching it for three (03) hours per a week is not sufficient to boost the writing proficiency.

In fact, it needs other skills to be integrated because they are fundamental in an EFL setting. In addition; students are not exposed much to different styles of writing; they do not practise neither writing at home (creativity) nor trained to read. There is not sufficient time for both teachers and students; the more teachers instruct; the more they feel that their learners become confused and ambiguous; for writing demands time and efforts.

Question 2: Does reading contribute to the development of writing?

$$
\begin{aligned}
& \text { Yes } \rightarrow 08 \\
& \text { No } \rightarrow 00
\end{aligned}
$$

$100 \%$ of the questioned teachers view that reading has a great impact on the way the learners compose and that it strongly contributes to the enhancement of the writing skill. It is greatly believed that there is no reading without writing well. Drafting helps learners be creative and it helps them be critical in thinking. Reading is very important in EFL settings because it enables students draft flawlessly and nothing can hinder their writing; i.e. via reading; learners acquire vocabulary; good style; and most importantly: they write using a critical mind.

When the students read; they build their own knowledge; that is to say; they become knowledgeable about different subject matters. When they read; they become aware of various structures; how paragraphs are constructed; how sentences are built up; and more importantly; they acquire vocabulary. Stotsky (1983: 630) notices that "better writers were better readers, better writers read more, better readers wrote more syntactically nature prose, and reading experiences improved writing more than grammar instruction or further writing exercises"; (cited in Teaching Writing Through the Competence Based Approach; Belbachir 2006). Similarly; Smith (1982) joins the same idea by stating that reading and writing are complementary to each other; "reading and writing are two skills that mirror each other, and they ought to be taught in such a way as to complement each other" (Smith, 1982: 56).

The teachers believe that reading contributes to the development of the writing skill by stating as follow:

- $\quad$ Reading broadens the students' own knowledge of different forms of writing.

- Through reading; the learners will develop a certain familiarity with language; and vocabulary will expand. 
- Moreover; reading boosts the students' ability to think; and therefore enhances their creativity in writing.

- Reading may help the learners expand their vocabulary repertoire and knowledge of the world.

- Reading can also help in developing students' writing styles.

- It expands students' ideas and structure which help them improve their writing skills.

Question 3: Does the teacher comment on the students' writing?

$$
\begin{aligned}
& \text { Yes } \rightarrow 08 \\
& \text { No } \rightarrow 00
\end{aligned}
$$

It is revealed that the teachers are aware of the importance of providing feedback to their students. It is agreed among all the questioned teachers that commenting on the students' written production is fundamental. In fact; it is essential because:

- Without offering comments; learners will not know how to tackle their errors.

- Providing feedback is a real opportunity for the students to review their compositions.

- It is crucial to let the students know that their compositions have been read.

Question 4: When doing feedback, what aspect of the composition does the teacher focus on (you can tick more than one box)
a- Grammar
b- Vocabulary
c- Ideas organization
d- Punctuation
e- Spelling

Table 1. Aspects Teachers Focus on When Providing Feedback

\begin{tabular}{ccc}
\hline Aspects & N & $\%$ \\
\hline A & 08 & 100 \\
B & 08 & 100 \\
C & 08 & 100 \\
D & 07 & 87.5 \\
E & 07 & 87.5 \\
\hline
\end{tabular}

When giving feedback; all the teachers (100\%) stress on grammar; vocabulary and ideas organization. $87.5 \%$ of the instructors emphasize on punctuation and spelling mistakes. As it is shown (see table 1); all the teachers seem to concentrate on grammar; vocabulary and ideas organization; because these aspects are the elements that build up a good language and therefore the mastery of the target skill. When responding to students' production; the teachers emphasize on the stated aspects just to boost their knowledge about how to write. The instructors also pay much attention to punctuation (mechanics of writing) and spelling mistakes; because they believe that a perfect language is constructed on grammar; vocabulary; punctuation and spelling. Thus; the majority of the teachers give much importance to all the aspects to promote the writing skill.

Question 5: Do the student use teacher's feedback?

Table 2. The Use of Feedback in the Writing Skill

\begin{tabular}{ccc}
\hline Options & N & $\%$ \\
\hline Yes & 65 & 81.25 \\
No & 15 & 18.25 \\
Total & 80 & 100 \\
\hline
\end{tabular}

The results show that the great majority of the students $81.25 \%$ use feedback. It is worth mentioning that responding to the students' compositions is exceedingly vital since a great deal of the learners in the EFL classes rely upon it and take it into account. However; focusing on the comments of the teachers might be harmful for the students because; the latter may not lead to the development of the learner autonomy; and they may regard the teachers' feedback as discouraging; however; $18.25 \%$ of the students do not use teachers' feedback; because some of the learners do not feel at ease when receiving it. Thus; these students need to know about the importance of providing feedback in both writing as a process and writing as a product. 
4. Pedagogical Implications and Recommendations

\subsection{Principles of Providing Teacher Feedback}

According to the research findings; feedback is very important and beneficial. Both teachers and students involved in the study showed their strong belief of its importance. Ferris and Roberts (2001) indicated that students who received no feedback were less able to self- edit their own texts than those who received either explicit or general feedback on their errors. Careful feedback is on language feature in a student draft is a key to effective written communication and can help students to be aware of their written texts.

When providing feedback; teachers can engage in language awareness activities that are based on students' writings. When responding to students' writing; teachers need to make the evaluation of writing less threatening through clear; positive and constructive comments. They would know that; it is always a good idea to inform students about something positive in their writing. Furthermore; emphasis could be as much as possible be put on content and organization of ideas leaving the mechanics of writing to later stages. Teachers would give students enough time and more opportunities allowing them to work extensively in collaborative writing response group and provide them with more instruction in writing and the teaching of writing to develop competence and confidence when tackling the writing process.

The following points to serve as guidelines and principles for our teachers:

1. Make feedback an integral part of the writing process.

2. Provide informative and explicit feedback.

3. Feedback could be more accurate; and more trustworthy.

4. Ask students to provide feedback to other students (peer feedback) with confidence that this feedback can be effective.

5. Students need to develop strategies for incorporating feedback in an effective and positive way.

6. Students show a greater degree of positive motivation if they receive feedback that considers positive comments.

7. Feedback is more significant to students if they feel they improve after receiving it.

\subsection{What to Emphasize: Content or From?}

Writing demands a conscious effort which usually has to be sustained over a considerable period of time. Therefore; commenting on the students' compositions help them discover their mistakes whether grammatical mistakes or spelling ones. However; teachers might avoid viewing a piece of writing primarily as a source of grammatical and spelling errors; because such a treatment may hinder the communicative aim and emphasizes form rather than content.

In writing; the teachers need to bear in mind that their role has shifted from an evaluator of the written product to a facilitator and co-participant in the writing process. They no longer "assign a piece of writing, collect it, correct or indicate errors and return it" (Raimes 1983: 262); but rather as assistant to help students to take responsibility as producers of texts. Since the stress of language is on function; the teachers need to be involved in the act of composing in order to help students produce coherent; meaningful and creative discourse; In other words; teachers should not only take into account the students productions but could negotiate meaning and collaborate with learners by helping meaning to develop the strategies. The teachers of writing need to be aware of the following issues:

1. Writing needs a lot of time to be developed.

2. Writing is a difficult and frustrating skill and students need to be provided with positive feedback to maintain an eagerness to work.

3. Writing and writing and writing again teach writing.

4. Students could be encouraged to consider the different steps of prewriting; drafting; revising etc...

5. Revising is the most important stage in the writing process because it is the stage where content and purpose are checked for the sake of clarity and appropriateness.

6. Students need to be made aware of the importance of reading to develop an accurate and effective communication in writing.

7. Students need to be encouraged to write multiple drafts and learn about their own preferred process in order to exploit and guide it.

8. Primacy of content; planning and ideas organization over grammar; vocabulary and the mechanics of writing.

9. Teachers would not put more focus on grammatical and lexical errors at early stages; but reserve them for the end stage of students' drafting after they have worked through their ideas and organizational issues.

10. Feedback could be motivating; helpful and formative indicating for each individual writer what his or her weaknesses and strengths in specific areas. Arndt (1993: 91-92) sees that "if teachers of writing see their major goal as helping their students become proficient writers they must provide for motive feedback which helps students review their work productively...; and they need to reduce students anxiety or apprehension about writing".

11. Opportunities could be provided for students to discuss the comments they receive and make them part of the writing process. 
4.3 The need for reading to reinforce writing

Students are advised to read on different topics in order to build knowledge about different subject matters. Student readers will acquire "new knowledge structures born of reading other texts on the same subject" Spack (1985); in other words; reading boosts the students' thoughts; broadens their ideas. So; in order to reinforce writing; teachers should facilitate students' acquisition of reading and writing skills to stimulate their creativity.

EFL learners need to practise a close reading and writing; so that they become skilled and competent at both disciplines. They need daily practice in order to overcome the obstacles that face them while writing (Paul and Elder, 2006). Meanwhile; they will deepen their knowledge about various stages of writing; and they will enrich their vocabulary. Furthermore; reading has a great impact on the other skills: listening and speaking; the learners will be able to speak because they already possess the vocabulary that they have already heard it. More importantly; they will be able to understand it when they listen to native speakers. The students need to be aware of the importance of reading in EFL setting. For; the latter is completely ignored in the department of foreign languages; section of English; in Sidi Bel Abbes; the students are not trained on how to read.

In addition; they do not know about the influence of reading on writing; that is why; they perform poorly; commit mistakes; translate words from L1 or L2 into English, lack of vocabulary. Most importantly; grammar seems troublesome and complex for them; i.e. they do not manage writing. Basically; they do not differentiate between tenses; for instance; when to use the present tense and simple past.

Thus; reading makes EFL students aware of various issues as far as errors are concerned. Through the latter; the learners become able to remedy all their problems including grammar which can be learnt via reading; in other words; without a teacher. Reading is a basic instrument for generating ideas about a particular topic in the writing class. It could be used as a prewriting activity that exposes the writer to vocabulary (Belbachir, 2006).

Pre-reading and post-reading foster critical thinking and help the students develop their own ideas for their composition. As Carrell and Connor (1991) stated that reading facilitates ESL writing; that is; students are encouraged to use reading in order to empower their writing skill; (Carrell and Connor 1991; cited in Belbachir, 2006). Therefore; teaching reading to second year LMD students of English is essential; since the latter enhances the writing skill.

\section{Conclusion}

The data and the obtained results show that the writing skill is complex in that it includes several issues and requires a variety of research strategies. A focus could be put on teaching writing as a process rather than the product since the latter appears at the end; in the sense that it is the final result of any process of writing. In other words; teachers need to stress on the first stages of the writing skill; and making teacher feedback the focal point because his/her role is to guide students through the writing process avoiding an emphasis on form to help them develop strategies for generating drafting and organizing ideas. The teachers need to make their learners aware of the importance of the reading skill; for it contributes to the development of the writing skill. Moreover; both teachers and learners are aware of the importance of providing positive feedback in the writing process. Thus; offering comments on the students' compositions lead to a better writing; since; it makes the learner aware of the errors and mistakes. Thus; the student reviews his/her composition.

\section{References}

Aridah, M. A. (2003). The Role of Feedback in the Teaching and Learning of Writing. CELTS, 3, $105-114$.

Arndt, V. (1993). Response to Writing: Using Feedback to Inform the Writing Process. In Brook and Walters. (1993) Teaching Composition Around the Pacific Rim. Politics and Pedagogy. Edited By Mark Nibrock and Larry Walters. Multilingual Matters Ltd.

Belbachir, S. (2006). Teaching Writing through the Competence Based Approach. Oran: Maouidouka Tarbaoui.

Ferris, D \& Roberts, B. (2001). Error Feedback in L2 Writing Classes. How Explicit Does it Need to be?. Journal of Second Language Writing, 10, 161-184.

Flower, L. (1994). The Construction of Negotiated Meaning: A Social Cognition Theory of Writing. Illinois: The Board of Trustees.

Flower, L. and Hayes, J. R. (1981). A Cognitive Process Theory of Writing. College Composition and Communication, 32(4), 365- 387.

Fulwiler, T. (1997). College Writing: A Personal Approach to Academic Writing (4 ${ }^{\text {th }}$ ed). Portsmouth: Boynton/ Cook Publishers.

Grabe, W, \& R.B Kaplan. (1996). Theory and Practice of writing. An Applied Linguistic Perspective. Addison Wesley Longman Limited.

Hamp Lyons, L. (1987). Study Writing: A Course in Written English for Academic and Professional Purposes. New York: Cambridge University Press.

Harmer, J. (1998). The Practice of English Language Teaching. Essex: Longman.

Hyland, K. (2003). Second Language Writing. Cambridge: Cambridge University Press. 
MacArthur, Ch. A., Graham, S., \& Fitzgerald, J. (2006). Handbook of Writing Research. New York: The Guilford Press.

Paul, R. \& Elder, L. (2006). How to Write a Paragraph: The Art of Substantive Writing. Cambridge: Cambridge University Press.

Raimes, A. (1983). Exploring Through Writing: A Process Approach to ESL Composition. Cambridge: Cambridge University Press.

Smit, D. W. (2004). The End of Composition Studies. Southern Illinois: The Board of Trustees.

Smith, F. (1982). Writing and the Writer. New York: Holt, Rinehart, \& Winston

Spack, R. (1985). Literature, Reading, Writing and E.S.L: Bridging the Gaps. TESOL Quartely, 19, 703-726.

Stotsky, S. (1983). Research on Reading/ Writing Relationships. A Synthesis and Suggested Directions, 49, 627-642.

Sommers, N. (1982). Responding to Student Writing. College Composition and Communication, 33(2), $148-156$.

Tyner, T. E. (2008). Writing Voyage: A Process Approach to Writing ( $8^{\text {th }}$ ed). Thomson: Wadsworth.

Weigle, S. C. (2002). Assessing Writing. Cambridge: J. Charles Alderson and Lyle. F. Bachman. 